\title{
Control System for Preheating of Molds with using PLC
}

\author{
P. Štefanec, M. Paškala, B. Dobrucký \\ Department of Mechatronics and Electronics, Faculty of Electrical Engineering, University of Žilina, Slovak \\ Republic
}

B. Šušlík

Continental Matador Rubber, s.r.o., Púchov, Slovak Republic

\begin{abstract}
This paper is dealing with the reconstruction of the control of preheating mold machine. Old system with relay devices for operation control is replaced by new electronic PLC one. There are designed and created a new electronic signal grid with fieldbus and new control system using programmable logic controllers (PLCs) as well as human-machine interface (HMI). They are used for control and setting parameters of preheating technology. New algorithms and programs for PLC and HMI have been created, and reparation of mechanical parts of the preheating machine has been performed. Device is after all make changes used for saving time in manufacture. Several kinds of regulators are described adaptive regulator including.
\end{abstract}

KEYWORD: Programmable logic controller; tire molds; control system; preheating; adaptive algorithm

\section{INTRODUCTION}

In industry in process production tires for cars use usually hydraulic compactors. Dependent of quality tire is high. Construction and type compactor device is variously, but everything has common features. Type of tires designates molds and chemical composition. Mold is made from high quality steel and is important part of devices. Chemical substances' composition for tire is mixing and connects with mechanical parts (iron wires etc.). In next technologic the raw product step is created. Its shape is similar as final product, but absent structured surface and have deficiently mechanical properties. For completion tire is need to insert raw tire into mold in hydraulic compactor, where important parameters in molding process are temperature and pressure. Complete manufacturing processes of tires are described in electronic document [1]. A part of Master Thesis [2] of the first author is a base for technology process control innovation in this paper.

\section{GETTING STARTED}

Molds gives shape for tires (design and tread profile). After insert mold into compactor the membrane will blow up and heating can start. In case if the value of the pressure or the temperature is incorrect, production process would be unsuccessful.
Heating the mold to the desired temperature, it takes 2-4 hours, according to the type of mold. Changing of molding tires type requires a change of the pressing mold. As a result, the deterioration in the efficiency of compression, since the initial heating up from room temperature to the desired (above $100^{\circ} \mathrm{C}$ ) can be serial produced by machine without the need of initial heating.
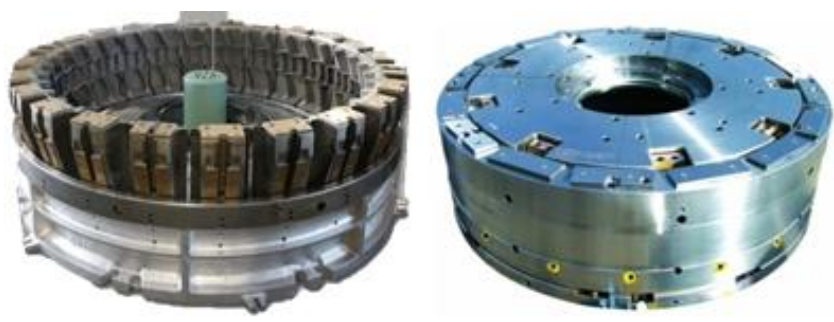

Figure 1. Vehicle tire molds.

After a while the preheating the tire is ready for further process (pressuring,...). Parameters of pressing machine for different types of tires are variously. However, it is essential to meet their specific values. When replacing of the mold this is grasped by the form handles and transferred using the forklift. There are two variants of exchange and warming of molds. The first one means the insertion of cold form into the pressing machine. The steam channels are activated and make possible steam flow around the mold and heating of device to the desired temperature. Then, the production begins by gradual inserting of blanks and it finishes by picking out of 
the products. This method has advantages in handling cold mold not with warm-up one. However, big disadvantage of the method is inefficiency, therefore the heating in the pressing machine means discontinuing producing process, due to warming up of the mold. The other option is the use of a device for molds preheating. An essential advantage of this method is time saving. The disadvantage is the handling with hot object; however, using protective equipment by operator the risk of injury is minimized. Comparing the two methods of warming-up the heating time is reduced by two thirds of the original one. The pressing machine is not uselessly blocked by initial warm-up. So, use of the preheating is more effective method. There is shown comparison of both molds heating methods and saving time in the Figure 2.

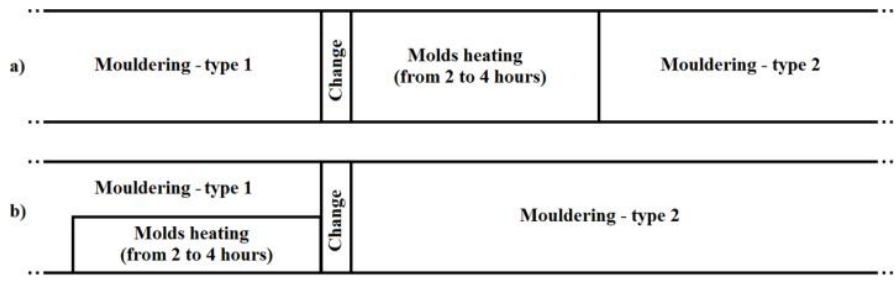

Figure 2. Caption of a typical figure. Photographs will be scanned by the printer. Always supply original photographs.

Preheating device contains several structural parts. The computer model is shown in Figure 3. Mechanical part consists of two identical mutually independent issues. Each of them, left and right part, has a heating container with vertical movement. When the container is in the uppermost position it can be secured by the lock. The movement and locking of the container are performed by means of pneumatic cylinders. The driving medium is compressed air. Marginal positions of the cylinder are detected by sensors with binary output status not by analogue one. Additional sensors are used to determine of the actual pressure of the compressed air and also the steam. Calorific medium is steam. Amount of steam is controlled by pneumatic valves. From a security point of view the safety rods are placed on the containers which are switched by activating contacts. Vertical movement of container is blocking by control system using activation of the safety roads. The device is operated by the control panel placed on a cubicle door. There are on control panel the switching elements that allow controlling of both sides of the preheating by individually way. It is also the possible to over switch the machine into manual mode, to control the movement and heating. Automation process is provided by a programmable logic controller PLC. Panel of human-machine interface HMI is used to adjust the values of temperature and heat-up time and is connected with the PLC by communication link. The panel is placed on the outer panel of the cabinet, too. The important condition states and performing of PLC are signaling by industry beacon.
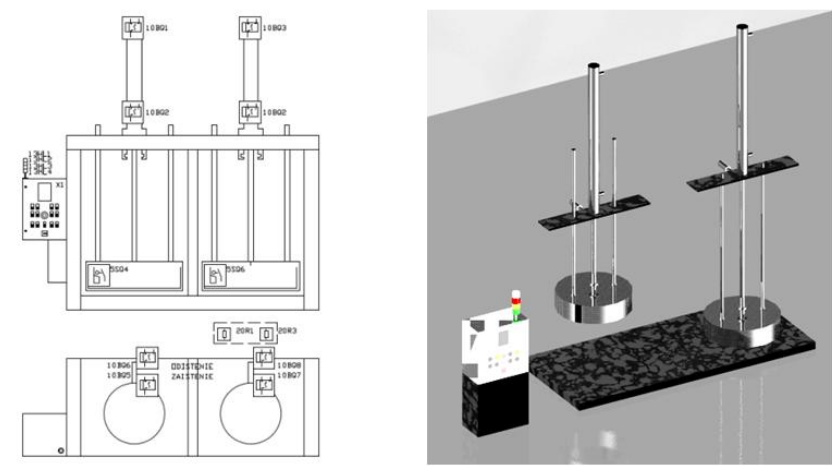

Figure 3. Computer model of preheating device.

The operation process with the device contains several steps. By manual work with the device the operator comes to switchboard and control panel to check if the air pressure and steam are correct; error messages on the display panel visualization are also checked. If error is indicated, it should be removed it is the cause and provide the confirmation.

Table 1. Choice of manually or/and automatically preheating control

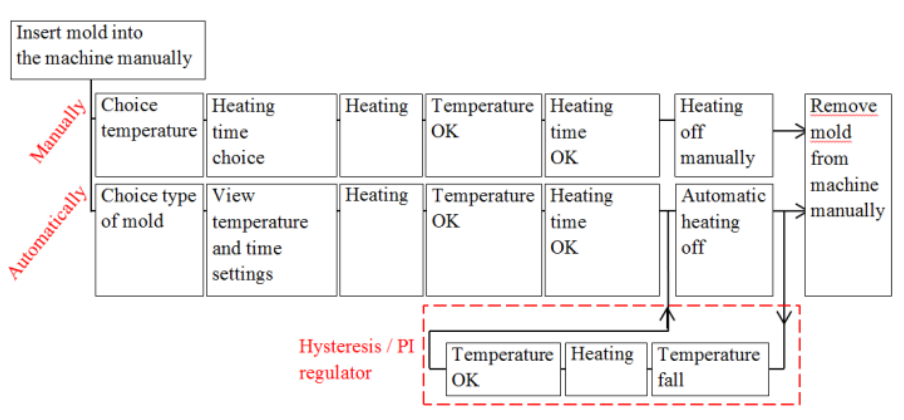

Further, if it isn't switched on the control voltage it must be turned on by pressing CONTROL VOLTAGE instantaneously with green LED light for CONTROL VOLTAGE. Control voltage is necessary for the implementation of the movement up and down of the container. Detailed description of manualy work is given in [2]. The choice between manual or automatic control of the preheating process is given in Table I. Automatized preheating control is descripted in the next Chapter 3.

\section{DESIGN OF AUTOMATIZED PREHEATING CONTROL}

In case when machine is automatically controlled the hysteresis- or PI regulator can be used for the control. Choice of the type of controller is generally affected by specific conditions. In industrial practice, in most cases we encounter one dimensional control circuits. One-dimensional control circuit has one control, one action and one controlled variable: 


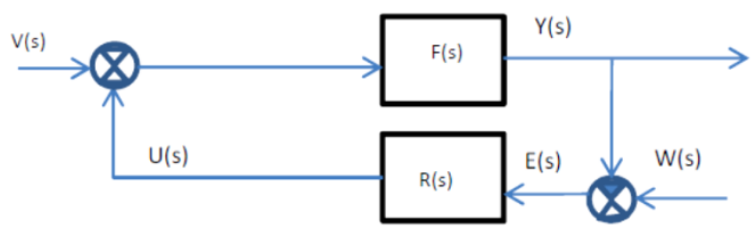

Figure 4 Block scheme of one-dimensional control circuit

where: F (s) - system image transfer; R (s) controller image transfer; W (s) - the image of the reference variable (resp. reference value); E (s) - the image of deviation (or error resp.); U (s) - image of action quantity; V (s) - disturbance variable image; Y (s) - control variable image.

In case, when transport delay is lot less as time constant of mold heating process and it can be negligible, the typical response of unit step is shown in Figure 5.

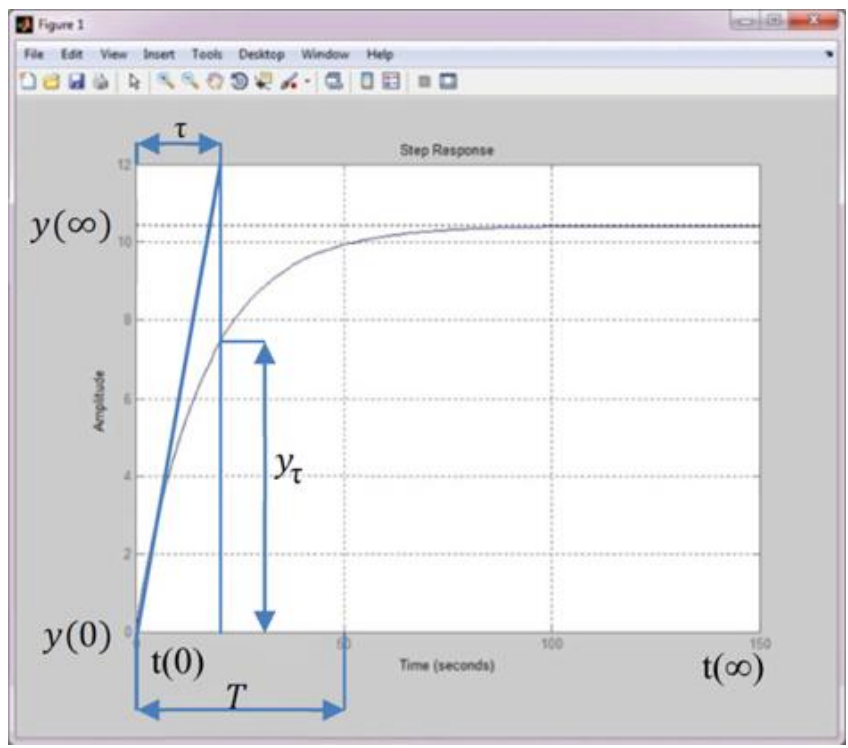

Figure 5 Typical response on unit step of input quantity without transport delay

So, the following equation for transfer function will be valid [3]:

$$
G(s)=\frac{K}{\tau . s+1},
$$

where: - $\mathrm{K}$ is gain defined as

$$
K=\frac{\Delta y}{\Delta t}=\frac{y(\infty)-y(0)}{t(\infty)-t(0)},
$$

- and $\tau$ is time constant whereby

$$
y_{\tau}=0.632 y(\infty) \text {. }
$$

Transport delay of heating molds is approximately 330 seconds and time constant about one hour (3 100 seconds) in that measuring when values are deduced from step response, see Fig 6.

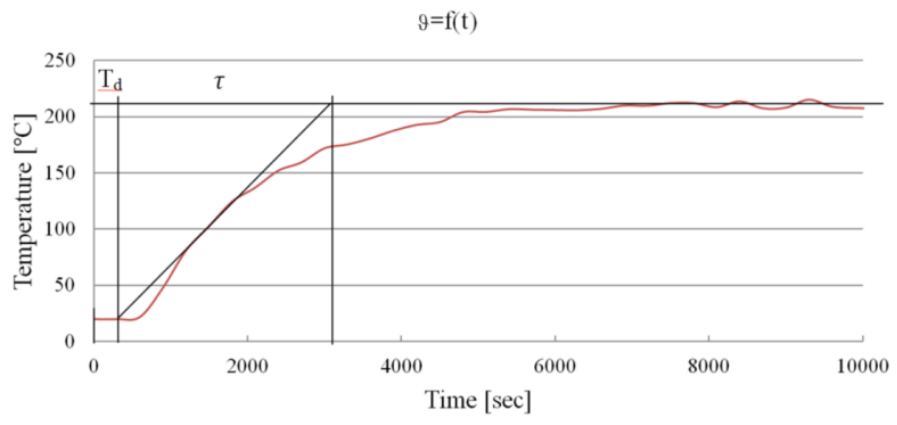

Figure 6: Measured step response of heating process on small type of mold

So, transport delay of heating mold process for small type of the molds could be negligible. Ripple of temperature function in steady state is caused by opening of trap valve.

Another problem of description of heating mold process occurs when transfer delay is comparable to time constant, and transfer function will be as [3], [4]

$$
G(s)=\frac{K}{\tau \cdot s+1} e^{-T_{d} s} .
$$

Where $\mathrm{K}$ is given by (2); value of transport delay $\mathrm{T}_{\mathrm{d}}$ could be defined as [4]:

$T_{D}=\frac{t_{2} \cdot \alpha-t_{1}}{\alpha-1}$,

where $\alpha$ is heat transfer coefficient $[\mathrm{W} /(\mathrm{m} 2 . \mathrm{K})]$ and its value is by [3], see Fig. 7:

$$
\alpha=\frac{\ln \frac{K-y_{1}}{K}}{\ln \frac{K-y_{2}}{K}} \text {. }
$$

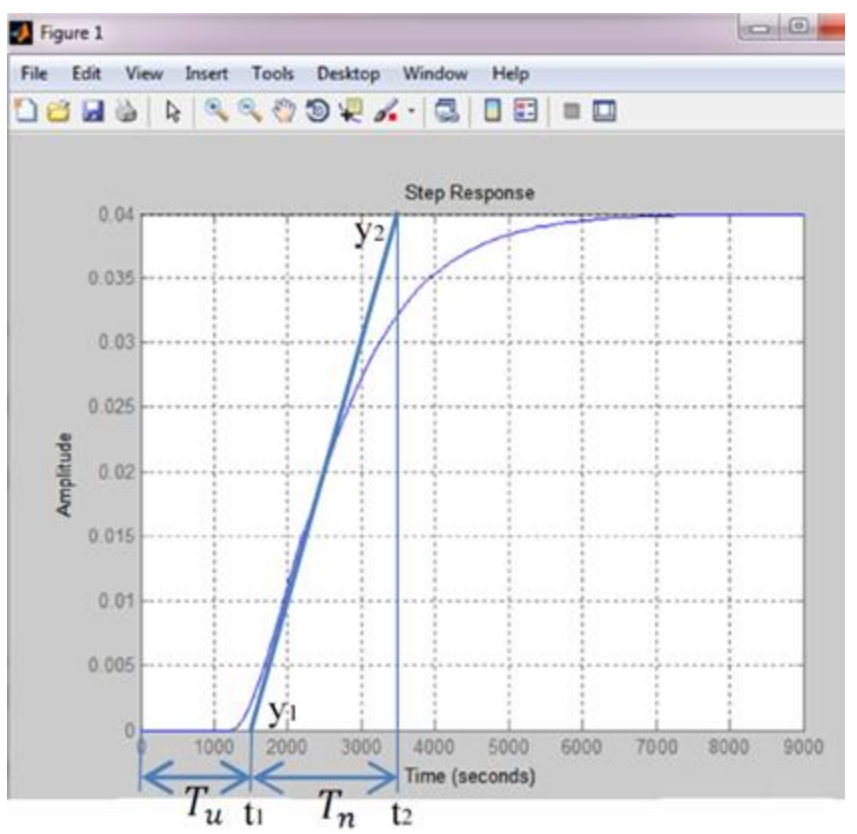

Figure 7. Response on step change of heating mold process with transport delay $\mathrm{T}_{\mathrm{d}}$

So far, the preheating process is controlled pneumatically switching to HEAT ON and HEAT OFF, respectively. To improve the control of heating 
process and use automatically mode of control (see Tab. I.) is needed to substitute pneumatic control devices by electrical/electronic once, first of all the pneumatic switch-on - switch-off valve should be replaced by proportional controlled electronic valve. Thus, it is possible to use hysteresis two-level orcontinuous control. Since the hysteresis controller features by restriction of switching frequency given by mechanical parts, and overshot given by hysteresis, continuous or discrete (numerical) PI/PS controller is advanced solution.

Using adaptive regulator, when the gain $K$ is dependent of regulation error, transient characteristic is without any overshoots. Step response with adaptive value of gain $K$ is shown in Fig. 8. Using adaptive controller the process will accelerate without overshoots, and with settling time of regulation which can be better than by classical method one. Value of variable $K$ should be calculated in each computation step.

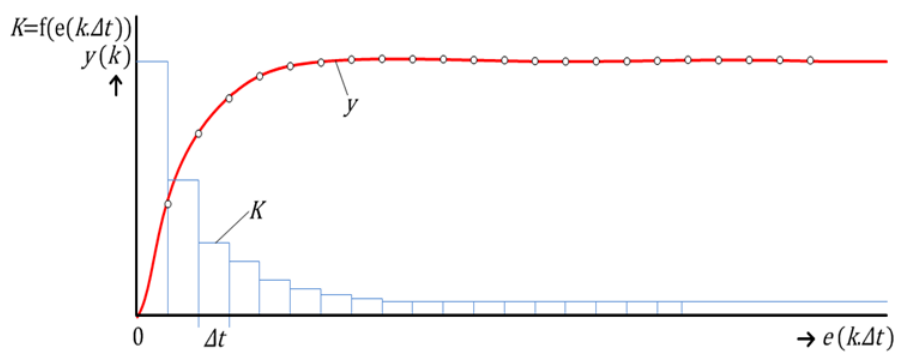

Figure 8. Principal waveform of step response with variable gain $K=f[e(k \Delta t)]$

Parameters of PI/PS regulator is assigned using classical design of control circuit synthesis methods [4], [5]. Such an adaptive control is to be provided using PLC devices, also.

Turning on of the switch selector to HEAT ON state on the panel starts the steam supplying to the circuit molds and begins the heating process. Actual status is indicated by lights for heating, pressure and mold-ready-indication, and by beacon and graphically on the visualization panel. If the heating process is necessary to stop for any reason, it can be done so by switching of HEAT switch to OFF. By reaching of the desired temperature begins countdown heating time. The remaining time is displayed on the screen of the HMI panel. After the time required to heat the valves controlled flow of steam remain open. The reason is to maintain temperature and long-term prevention of cooling of the mold.

Signaling of heating is indicated with signal lights on control panel and also by yellow light of the beacon.
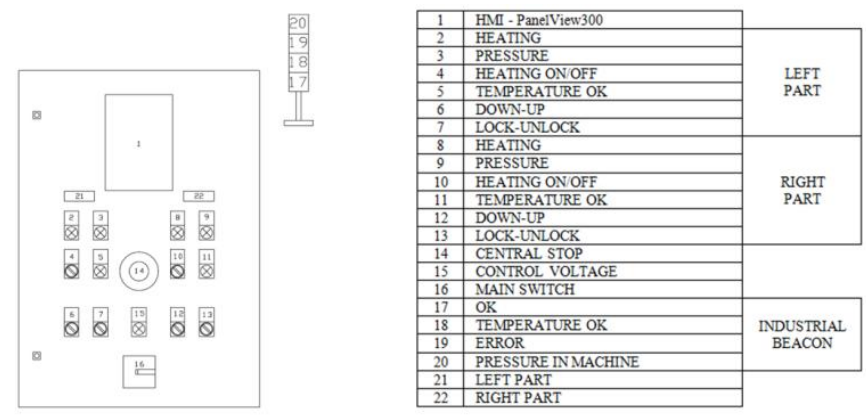

Figure 9. Control panel and signalization lights

The orange beacon light indicates two states of a heated mold, whether left or right one or both molds were warming-up. Blue color indicates the presence of steam pressure in the device - PRESSURE, trouble-free green $\mathrm{OK}$ status, and the red error alarm.

PLC and electromechanical parts description and their parameters or properties, respectively, are given in datasheets (see [2], [6]-[10]). In this section are quoted just main ones.

\section{Parameters of PLC}

- processor 1747-L532C/D 5/03 CPU - 16K Mem, Allen-Bradley, [6]

- digital input module 1746-IB32, 32-Input(SINK) 24VDC, Allen-Bradley, [7]

- analog input module 1746-NR2 Analog 4Ch, RTD/AMCI-153x, Allen-Bradley, [8]

- digital output module 1764-OW16, 16-Output (RLY) 24VAC, [9]

- power supply for PLC 1746-A7, Allen-Bradley, [6]

- operator panel PanelView300, [10]

\section{Digital inputs}

- sensor air pressure - PEV 1/4-B-OD, FESTO

- safety manostat for steam pressure measuring, xmlbs35r2s11, Schneider Electric

- magnetic sensor of position, SME-1-S-LED-24-K$\mathrm{B}$,

\section{FESTO}

- magnetic sensor of position, SME-8-1-S-LED-24, FESTO

- undoable two position rotary switch, XB5-AD21,

Telemecanique

- undoable three position rotary switch, XB5-AJ53, Telemecanique

- backlit button, XB5-AW33B5, Telemecanique

- central stop button, XB5-AS8445, ZBY-9101, Telemecanique

- end limit switch with safety rod, ZCKE67, Telemecanique

\section{Analog input}

- condensate water sensor, 7MC1006-2DA1, Telemecanique 


\section{Digital output}

- light signalization, XB5-AVB1, XB5-AVB5, XB5-AVB6, Telemecanique

- industry beacon, XVAC331, XVAC351, XVAC341, XVAC361, Telemecanique

- compressed air terminal, CPV6, FESTO

- air valve, MFH 5/3G-D-3-C, FESTO.

\section{PROGRAMMING PLC CONTROLLERS}

RSLogix500 environment is a standard tool for creating PLC program from the Allen-Bradley manufacturer. First, the analysis of all possible states in which the device can be operated. The analysis is necessary to the proper function of management technology. Whereby, a list of possible errors can be compiled. The program is divided into the main program and subsequent subprograms. Beginning of the main program, two bits control the internal auxiliary bit B3: 0th Bit B3: 0 is used as a virtual state "1" and "0". In the first line instruction "SET" sets B3: 0 permanently into a state of logical level one, and the second line is setting contrary to the zero state. Further follow routines which their number is eight in total; some of them are described below.

The first subroutine means 3RESTART of the program. All the necessary bits to the basic state are setting. By turn-off and restarting device could cause the mechanical displacement of the individual moving parts, it is necessary to restart until the real output actual states are entered into the registers. By entering into the subroutine is used instruction "First Pass", which will always be performed only at the first operating cycle; thus only once. All bits of output cards OW16 are setting in the subroutine. The values of heating time are written into registers with the value "120" that mean the basic time 120 minutes. Next instructions are used to ascertaining the pneumatic cylinders real state positions and their writing into internal registers. At the end the left and right side of the device heating states are written as well as also signaling of individual containers heating.

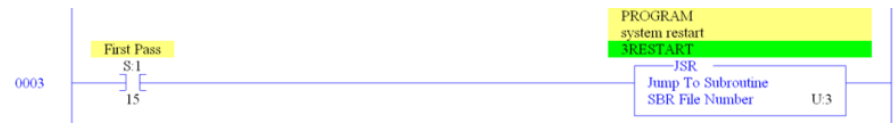

Figure 10. Example of program part with instructions First Pass and Jump to Subroutine

The second subroutine is 4MOVES. It watches and controls the vertical movements of containers and locks it at the top position. Any error must be handled and its flag removed. Container must be in down position before starting of the heating. However, in practice following problem can occur in case the container has remained in the top position:
The container falls down by own weight bypassed of pneumatic cylinder. The lock is impossible to unlock in this state. Unlocking by the device is possible with button "Start control voltage" pressing and switchover the switch movement in UP position. After this act the device works in normal mode.

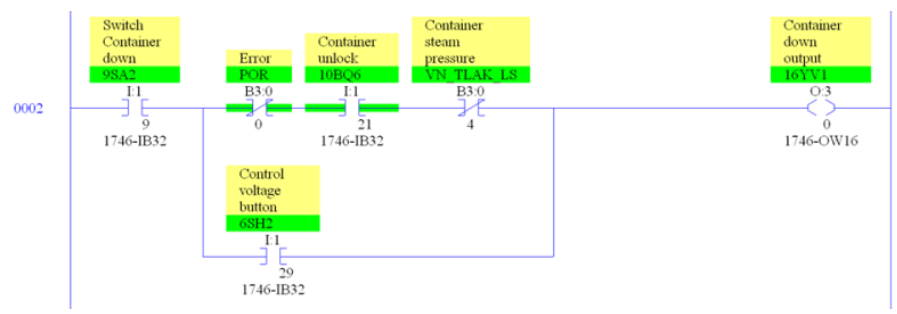

Figure 11. Vertical movement and unblocking machine program

Next program is created for alert signalization. If container is down and heated the move of container is not possible and by switch changeover is displayed error on HMI panel. The move is also blocked in case of presence of the steam in device. Locking and unlocking of the container is only allowed when container is in the top position. This condition defends before crash the container from bottom side to the lock.

The third subroutine is 5TEMPERATURE. The demanded values of time and temperature of heating are to be setting. Timer instructions are used for generating of pulses in minute intervals. Possibility of corrections of analog temperature sensors are necessary because of sensor deviation sometimes appears. Turning on of the heating requires the following conditions filling: heating switch at $\mathrm{ON}$ position; container must be in the down position and no error of device should be announced. Otherwise, the heating will not turned on and the error message will be displayed. Switching heating switch to OFF position the steam delivery is immediately stopped and the timer is reset into " 0 " value. If the button TOTAL STOP is pressed during heating and forthwith deactivated, heating time register is set by the default value "120". Subsequently is calculated remaining heating time of the mold. Reaching the desired temperature the remaining heating time is zero and state "Mold is warmed" is activated.

The subroutine for analogue module, error subroutines and processor programming module are not possible to describe in detail within this paper.

\section{PROGRAM FOR HMI}

Visualization is created in a developing environment PanelBuilder32. The program consists of the main screen and secondary screens. PanelBuilder32 environment allows insert many kinds of elements to the display as static text, dynamic text, entry fields, graphics and similar ones [10]. Selection screen is 
provided by the function keys $\mathrm{F} 1$ through $\mathrm{F} 8$. The main screen shows the current temperature $\left[{ }^{\circ} \mathrm{C}\right]$ in the form of a decimal number and also the remaining heating time in minutes. Pressing F1, F2, F3 the change of settings of heating parameters; the status of inputs and outputs and error messages are displayed on the subscreens.

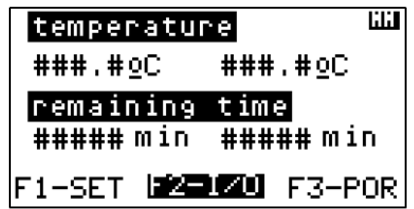

a)

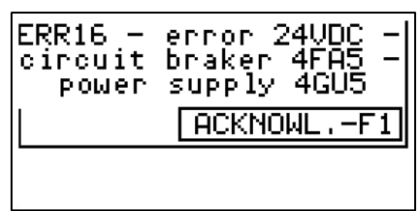

b)
Figure 12. The main screen of HMI a) and error reporting b)

There are displayed on sub-screens the values and/or states of device: sensors, lights, pneumatics coils and their parameters. Last two types of screens indicate errors messages and hardware settings of PanelView300; the brightness of the display, standby time, etc. is possible to adjust. Messages errors are collated chronologically.

\section{EXPERIMENTAL VERIFICATION}

Last part of reconstruction process is control system realization and verification. Electronic components are placed and connected on the mounting plate of instrument panel. Electrical elements are implanted into door of switchgear; the industry beacon is on the top of the box, see Fig 10.
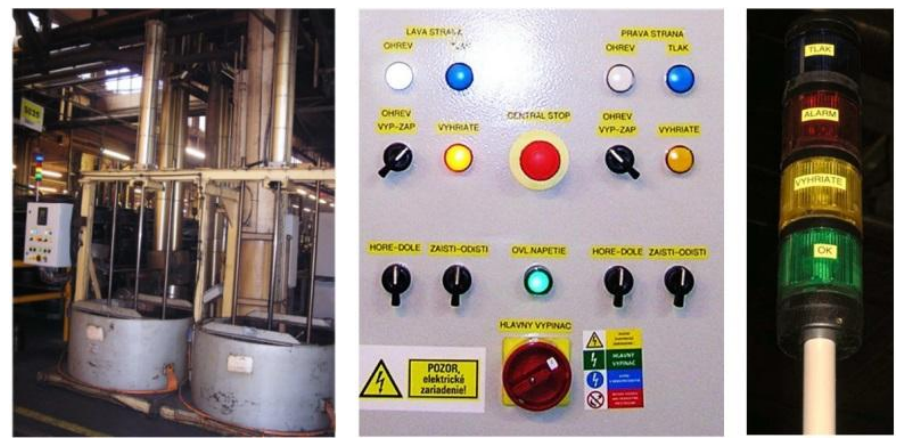

Figure 13. View of the machine after reconstruction, control panel and industry beacon (with Slovak labels)

Subsequently, the programs for PLC system and HMI are tested. All discovered errors should have been corrected. After all this steps the device can be commissioned into operation of manufacturing process of tires.

\section{CONCLUSION}

Device works after reconstruction properly and saves the time. In the future, PLC controllers with HMI can be connected to management system of production of tires. The controllers connected by LAN bus are to be send data of errors and critical states. To evaluate the efficiency of pressing machine could be used the information regarding to the time of the mold preheating which brings mentioned time saving.

\section{ACKNOWLEDGEMENT}

The authors wish to thank for the financial support to the Slovak Agency for Research and Development by the grant No. APVV-0314-12.

\section{REFERENCES}

[1] Kaster \& Lynch (2014) Tire Manufacturing Processes, http://tirefailures.com/PDF_vf/whitepaper.pdf.

[2] Štefanec, P. (2014) Design of control system for molds preheating (in Slovak: Návrh riadiaceho systému predohrevu foriem). Master Thesis, Faculty of Electrical Engineering, University of Žilina, Slovak Republic.

[3] Bystričanová, A. (2014) Control of flexible production systems (in Slovak: Riadenie flexibilných produkčných sústav, PhD. Dissertation, Faculty of Electrical Engineering, University of Žilina, Slovak Republic.

[4] Végh, P. (2009) Collection of the solved tasks and assignments of automatic control theory with simulations in MATLAB and Simulink (in Slovak: Zbierka riešených úloh a zadaní $\mathrm{z}$ teórie automatického riadenia so simuláciami v prostredí MATLAB a SIMULINK“), STU, Slovak Republic.

[5] Madarász, L. and collective (2010) Basics of Automatic Control (in Slovak: Základy automatického riadenia), ELFA, s.r.o., Košice, Slovak Republic.

[6] SLC-500TM Advanced Programing Software _AllenBradley (Cat. No 1747-PA2E) (2008) Publication 1747UM011G-EN-P.

[7] SLC-500TM RTD/Resistance Input Module - User Manual Allen-Bradley (Cat. No 1746-NR4) (2002) Publication 1746-IN007C-EN-P.

[8] SLC-500TM Analog I/O Modules Software - User Manual Allen-Bradley (Cat. No 1746-NI4, -NI8) (1999) Publication 1746-UM001A-US-P.

[9] Panel Builder Software - User Manual Allen-Bradley (Cat. No 2711-ND3) (1998) Publication 2711-6.0.

[10] Panel View Standard Operator Terminals, Publication 2711-UM014E-EN-P (2008) Publication 2711-UM014GEN-P. 